\title{
Experimental Study of the Wet Cooling Tower using Different Packing Materials
}

\author{
Alaa H. Hussein ${ }^{1}$, Safaa H. Faisal ${ }^{2}$, Bassam A. Mohammed ${ }^{3}$ \\ \{alaahamel2@gmail.com¹, s_hfaisal100@stu.edu.iq ${ }^{2 *}$, Bassam.moh@stu.edu.iq\} \\ Thermal Mechanical Engineering Department., Southern Technical University, Basra, Iraq ${ }^{1,2,3}$
}

\begin{abstract}
Three alternative materials are suggested to use in the wet cooling tower as a replacement to the standard plastic packing (PL). These are reed plants (RP), drinking water bottlenecks (WB), and chicken feathers (CF). Results show that increasing the airflow rate leads to an improvement in thermal performance together with an increase in pressure drop. Increasing the water flow rate negatively affects the thermal performance with a slight increase in the pressure drop. The increase in inlet water temperature does not show any effect on the pressure drop. It is found that the PL packing is the best in terms of thermal performance, followed by the RP packing. The CF packing comes in the next, and finally, the WB has the lowest performance. The WB packing is the best in terms of pressure drop, followed by CF packing and then the PL packing, while the RP has the highest pressure drop.
\end{abstract}

Keywords: Cooling tower, Counterflow, Packing, Tower efficiency, Pressure drop.

\section{Introduction}

Many air conditioning systems, industrial processes, and thermal power plants produce large amounts of waste heat that must be removed and dissipated. Water is the best environment used to remove that waste heat from the respective heat exchangers. This may be done by drawing a continuous stream of water from a nearby source of water, heating it during the process, and then draining it back to the same source of the cooling water. The idea of using cooling towers in many industrial establishments came to remove heat directly from the atmosphere, thus saving large quantities of cooling water and recycling it again [1]. The common working principle of the cooling tower is to remove the heat energy from the hot cooling water using direct contact with cold air and expel it to the atmosphere while some applications use indirect cooling. There are two types of cooling towers: natural cooling towers and mechanical cooling towers. The latter has two types: forced draft or induced draft. The cooling tower consists mainly of several important parts including the water spray system, fillers, and fans. The water spray system is located at the top of the tower, and it receives hot water. The packing function is to increase the surface area of water droplet precipitation and increase the period of contact with air. Fans are used to push air into or absorb it from the tower, which increases the process of evaporation and thereby boost heat dissipation [1].

Throughout the cooling tower, two processes occur between air and water streams which are heat and mass transfer. The properties of air entering the cooling tower plays an important role in the evaporation process. Many studies are introduced to improve and represent the thermal performance of the cooling tower. 
Merkel's work [2] in (1925) can be considered a pioneer in this field as she combined the equations covering mass and energy transfer into the single equations based on enthalpy potential. Baker and Shryock[3] explained in detail Merkel's approach and applied it to several cases of cooling towers. Jaber and Webb[4] developed the effectiveness-NTU theory to be applied for designing the cooling tower. Elsarrag [5] used a burned clay as a filler in cooling towers and developed a correlation for mass transfer coefficient. Gharagheizi et al [6] studied and compared the cooling tower characteristics using two types of film fillers. It was concluded that the type and arrangement of packing influence the efficiency of the cooling tower. Mahmood et al [7] study the thermal performance of the counter flow cooling tower using three types of packaging, plastic sheets, aluminium sheets, and plastic balls. They found that aluminium packing gives the highest performance while the lowest is attained for plastic balls. Lemouari et al [8] conducted an experimental analysis of a cooling tower packed with galvanized sheets having a vertical grid in a zigzag form. They claimed that this arrangement possesses good mass and heat transfer characteristics comparing with other types of packing. Abbas[9] used a steel filler with two arrangements parallel and grid shapes in a counter flow cooling tower. He shows that the temperature of the water entering the tower has a great influence on the thermal performance. Kariem [10] study the possibility of reducing the evaporation rate from the dry-wet cooling tower combination system. Four corrugated packing shapes were adopted with all possible combinations. The results show that series configuration produces lower evaporation rates. Ghazani et al [11] used a laboratory-scale wet counter-flow cooling tower to examine the performance in the light of the first and second law of thermodynamic. The results showed that the irreversibility along the height of the tower depends on the mass ratio of water-to-air. Chen et al [12] compare the performance of cooling towers that used fresh bamboo mesh filler in the cooling tower with that in service for nine years. The results showed that although some mechanical properties of the used packing are decreased, it still met the normal requirements. Kong [13] used a foamed ceramic corrugated board packaging in a wet counter-flow cooling tower. They found that the range of cooling water and its efficiency decrease with increasing water to air flow mass ratio.

In this work, the performance of the counter flow wet cooling tower is studied and analysed experimentally using four different packing materials. The reference packing material is plastic packages (PL) and the suggested packing materials are reed plant (RP), drinking water bottlenecks (WB), and chicken feather waste (CF). These packings are chosen due to their low cost, lightweight, and local availability. Besides, the use of such alternative materials can solve an environmental and social problem, as it leads to a reduction in the level of pollution they cause.

\section{Experimental Works}

\subsection{Experimental setup}

The practical experiments of the present study are carried out using a laboratory-scale cooling tower. The apparatus as shown in Fig 1 is a counter flow, forced draught wet cooling tower. It can perform all operation conditions required by the present study. It mainly consists of:

1- Cooling tower column. 
2- Basin to collect cold water exit from cooling tower column.

3- Hot water tank made of galvanized iron sheets and supplied with an electric heater.

4- Make up a water system to compensate for water losses during the evaporation process.

5- Hot water circulating pump.

6- Hot water spray system that is placed at the top of the tower column.

7- Forced draught Fan to push the air into the tower.

8- Water flow meter.

9- Eliminator.

10-Thermocouple sensors to measure 6 points of temperatures for air and water.

The specifications of each part of the cooling tower are given in Table 1, while the specifications of different measuring devices that have been used are given in Table 2.

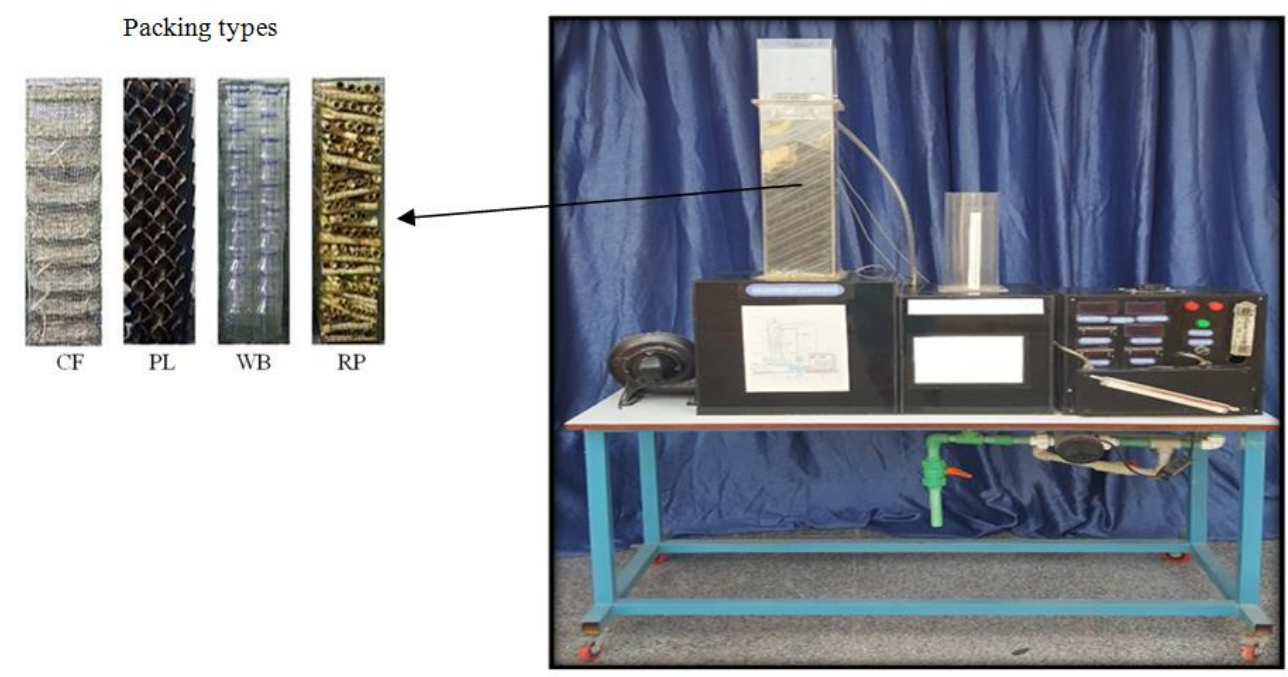

Fig. 1. Laboratory scale cooling tower and the used packing types.

Table 1. Specification of the cooling tower.

\begin{tabular}{ll}
\hline \multicolumn{1}{c}{ Part } & \multicolumn{1}{c}{ Specification } \\
\hline Cooling tower column & Made of plastic sheet $(15 \mathrm{~cm} * 15 \mathrm{~cm}) * 60 \mathrm{~cm}$ high. \\
Circulating water pump & $120 \mathrm{~W}, 230 \mathrm{~V}, 50 \mathrm{~Hz}$, max capacity $0.067 \mathrm{~kg} / \mathrm{s}$. \\
Packing to be used & $(14 \mathrm{~cm} * 14 \mathrm{~cm}) * 50 \mathrm{~cm}$ high. \\
Main heater power & $2.5 \mathrm{KW}, 230 \mathrm{~V}, 50 \mathrm{~Hz}$. \\
Forced draft fan & $260 \mathrm{~W}, 230 \mathrm{~V}, 50 \mathrm{~Hz}, 3000$ r.p.m, max capacity $0.086 \mathrm{~kg} / \mathrm{s}$. \\
Hot water tank & $(31 * 28 * 28) \mathrm{cm}$. \\
Coldwater basin & $(34 \mathrm{~cm} * 32) * 12 \mathrm{~cm}$ high. \\
\hline
\end{tabular}

Table 2. Specifications of different measuring devices.

\begin{tabular}{llll}
\hline \multicolumn{1}{c}{ Device } & \multicolumn{1}{c}{ Type-Model } & \multicolumn{1}{c}{ Range } & \multicolumn{1}{c}{ Accuracy } \\
\hline Thermo-Anemometer & Turbine type-Model AN100 & $0.40-30 \mathrm{~m} / \mathrm{s}$ & $\pm 3 \%+0.20 \mathrm{~m} / \mathrm{s}$ \\
Water flow meter & Float type & $0 \sim 18 \mathrm{~L} . P . M$ & $\pm 4 \%$ \\
$\begin{array}{l}\text { Differential pressure } \\
\text { drops }\end{array}$ & Digital type-model GM520 & $\pm 35 \mathrm{kPa}, \mathrm{LCD}$ display & $+0.3 \% \mathrm{FSO}$
\end{tabular}




\begin{tabular}{llll} 
Humidity & Digital type-Model GM & $\mathrm{RH}=0 \sim 99.9 \%$ & $\pm 2.0{ }^{\circ} \mathrm{C} \pm 0.4{ }^{\circ} \mathrm{C}$ \\
\&Temperature Meter & 1361 & $\mathrm{~T}=-50 \sim 1200{ }^{\circ} \mathrm{C}$ & $\pm 5 \%$ \\
\hline
\end{tabular}

Referring to Fig 2. The description of air and water circuits found while the cooling tower in operation is as follows:

A. Water Circuit: The warm water is pumped from the main tank (supplied with heaters) and passes through the control valve to the top of the tower column. The water is sprayed via the water spray system and falls onto the packing. The water is cooled by exchanging heat and mass with air. Finally, it is collected in the water basin located down the tower column. Measurements include mass flow rate, inlet water temperature $T_{\text {in }}$, and exit temperature $T_{\text {out }}$. Make-up water is supplied automatically by a compensation system located near the tower column.

B. Air Circuit: The forced draught blows the air into the tower column from the left side. Measurement includes mass flow rate, dry bulb temperature at the inlet $T_{a 1}$ and exit $T_{a 2}$, wet bulb temperature at the inlet $T_{w b 1}$ and exit $T_{w b 2}$. As air flows through the packed column, the moisture content starts to increase, and the water will cool down. Before the air leaves the top of the column, it passes through an eliminator; and finally, the air is discharged to the atmosphere. 


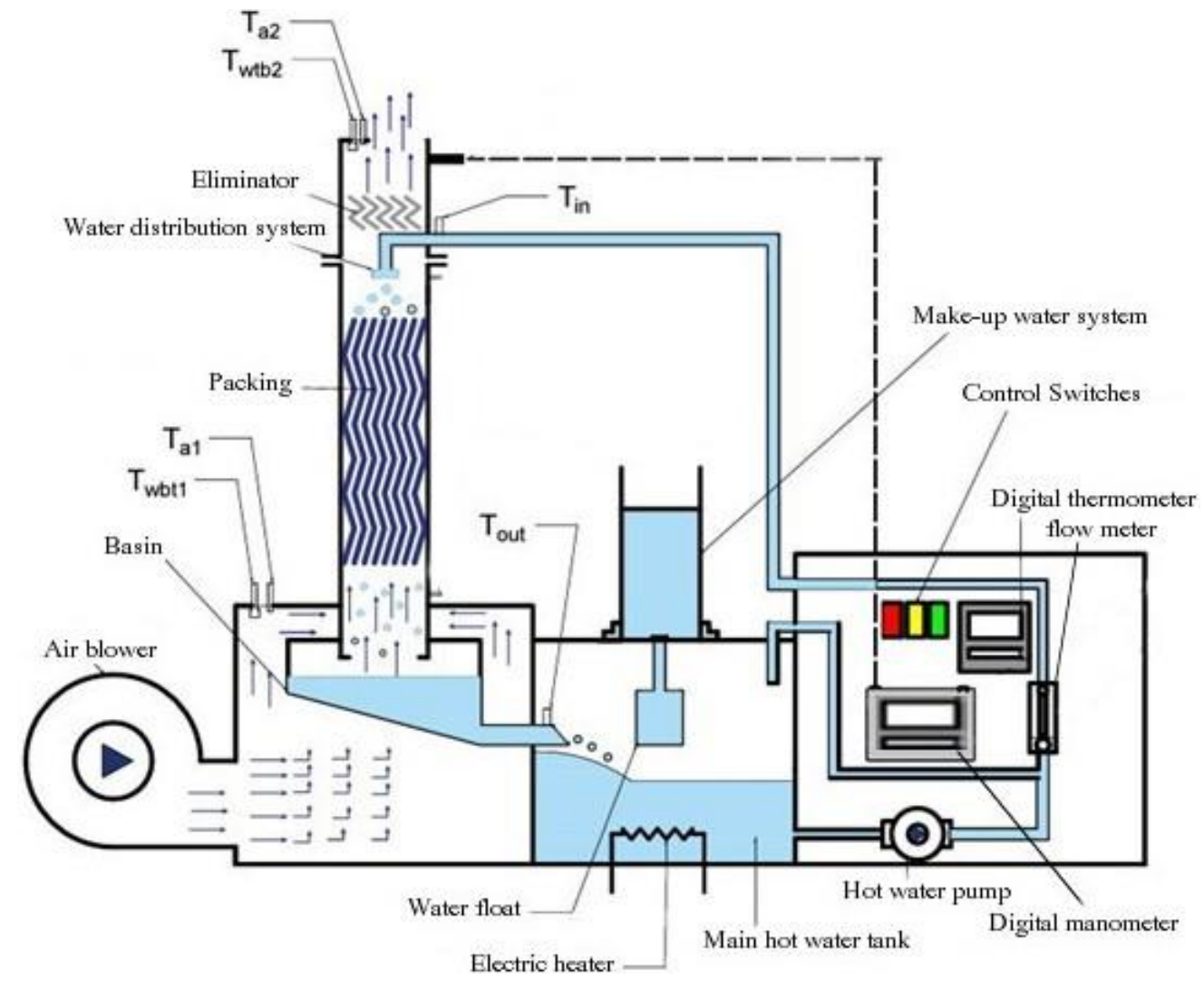

Fig. 2. Schematic diagram of the laboratory scale cooling tower.

\subsection{Operation conditions}

The operation condition covered by the present study includes hot water flow rates $0.025,0.033 .0 .05$, and $0.0678 \mathrm{~kg} / \mathrm{s}$, inlet hot water temperatures 45,47 , and $49^{\circ} \mathrm{C}$, and air mass flow rates $0.037,0.066$, and $0.086 \mathrm{~kg} / \mathrm{m}$. The experiments were done at an ambient air temperature of $28^{\circ} \mathrm{C}$ dry-bulb temperature and $16^{\circ}$ of wet-bulb temperature.

\subsection{Experimental procedure}

At first, the water in the main tank is heated before its ingoing the tower. After the required temperature of the water is attained, the pumping is started to the top of the tower at the required rate. At the same time, the fan mounted is started to force the required airflow rate into the tower. The steady-state is ensured by recognizing the water temperatures. When these temperatures are varying by just $0.1{ }^{\circ} \mathrm{C}$, then steady-state has been achieved. The time interval needed is about 10-15 minutes. This procedure is repeated for other values of hot water temperature, water, and airflow rates. 


\subsection{Data reduction}

The air mass flow rate $G$ is calculated from the continuity equation as:

$\mathrm{G}=\mathrm{V} \cdot \mathrm{A} \cdot \frac{\mathrm{P}_{\mathrm{air}}}{287 *\left(\mathrm{~T}_{\mathrm{a} 1+273}\right)}$

Where $\mathrm{V}$ is the air velocity and $\mathrm{A}$ is the area of the fan duct. the value of atmospheric pressure $\mathrm{P}_{\mathrm{air}}$ is assumed $101325 \mathrm{~Pa}$.

The cooling tower range is the temperature difference between the hot water inlet and outlet:

Range $=\mathrm{T}_{\text {in }}-\mathrm{T}_{\text {out }}$

The approach is the difference between the hot water outlet temperature and the ambient wet bulb temperature:

Approach $=\mathrm{T}_{\text {out }}-\mathrm{T}_{\mathrm{wb} 1}$

The cooling tower efficiency $\eta$ is the ratio of the actual temperature range to the ideal range, which is the sum of actual range plus approach [1]:

$\eta=\frac{\text { Range }}{\text { Range }+ \text { Approach }}=\frac{\mathrm{T}_{\text {in }}-\mathrm{T}_{\text {out }}}{\mathrm{T}_{\mathrm{in}}-\mathrm{T}_{\mathrm{wb} 1}}$

The heat load of cooling water $Q$ is found by thermodynamic heat balance equation [1]:

$\mathrm{Q}=\mathrm{L} \cdot \mathrm{Cp}_{\mathrm{w}} \cdot\left(\mathrm{T}_{\mathrm{in}}-\mathrm{T}_{\text {out }}\right)=\mathrm{G} \cdot\left(\mathrm{h}_{\mathrm{a} 2}-\mathrm{h}_{\mathrm{a} 1}\right)$

Where $\mathrm{L}$ is the water mass flow rate, $\mathrm{Cp}_{\mathrm{w}}$ is the specific heat of hot, and $\mathrm{h}_{\mathrm{a} 2}-\mathrm{h}_{\mathrm{a} 1}$ is enthalpy difference of air at inlet and outlet.

The tower characteristic or so-called number of transfer units NTU is defined as [1]:

$\mathrm{NTU}=\int_{\mathrm{T}_{\mathrm{a} 1}}^{\mathrm{T}_{\mathrm{a} 2}} \frac{\mathrm{Cp}_{\mathrm{w}}}{\left(\mathrm{h}_{\mathrm{s}}-\mathrm{h}_{\mathrm{a}}\right)} \mathrm{dT}$

Where $h_{s}$ is the enthalpy of saturated air and $h_{a}$ is the enthalpy of unsaturated air.

The evaporation rate $\dot{\mathrm{m}}_{\mathrm{eva}}$ is found from:

$\dot{\mathrm{m}}_{\mathrm{eva}}=\mathrm{G} \cdot\left(\omega_{\mathrm{a} 2}-\omega_{\mathrm{a} 1}\right)$

Where $\omega$ is the humidity content of the air.

\section{Results and discussion}

Fig 3. (a, b, c, and d) is for the number of transfer units and tower efficiency as they vary with air and water mass flow rates for the four tested packing s. All the curves are drawn for fixed inlet temperatures of the hot water and cold air. 

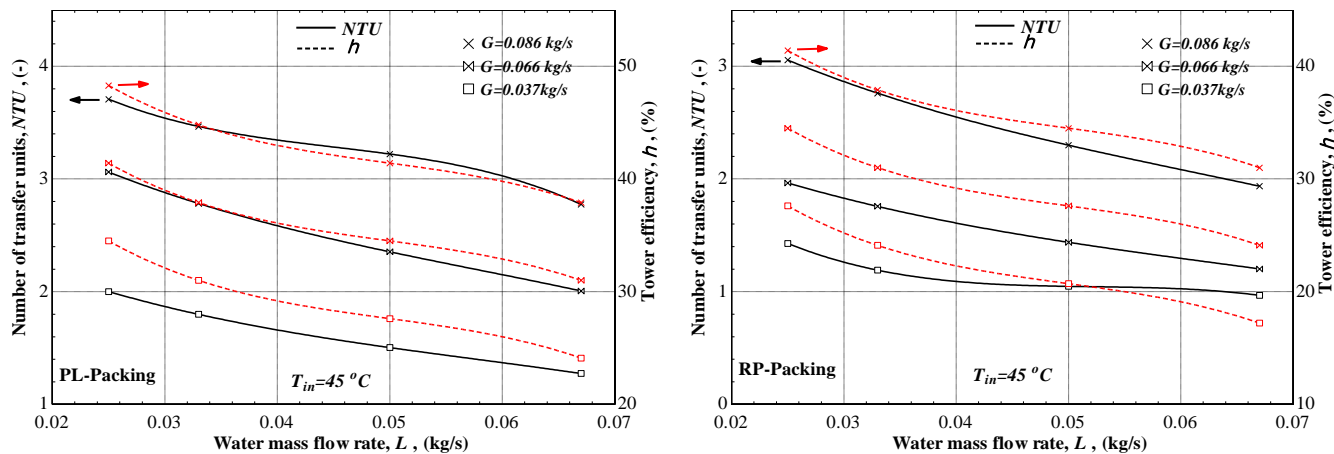

$-\mathrm{a}-$

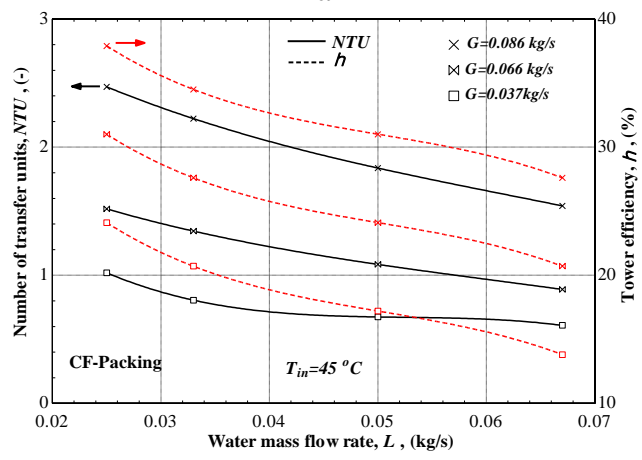

$-\mathrm{c}-$

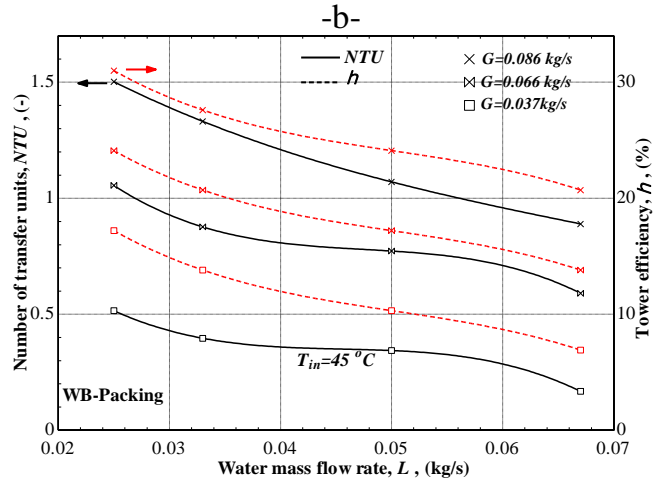

-d-

Fig. 3. The variation of NTU and tower efficiency with air and water mass flow rates (-a- PL, -b- RP, -c- CF, and -d- WB packing).

It is clear from the figure that increasing air mass flow rate has a positive effect while the water mass flow rate hurts both the NTU and tower efficiency for all the tested packing $\mathrm{s}$. This is quite understood, and it coincides with the results found in the literature related to this subject. Increasing the airflow rate will improve the heat and mass transfer due to increasing the evaporative rate. More air will be in contact with less water and certainly, this is a good situation for the cooling tower. By fixing the inlet conditions of hot water and cold air, then the tower efficiency will be a function of tower range only. The sum of range and approach which is the ideal rage is constant in this case. The increase of the airflow rate will make the range higher due to declining the outlet temperature of the water. of course, this will increase the tower efficiency as the air mass flow rate increase. The figure shows that the standard PL packing shows the best performance concerning the value of NTU and tower efficiency. The lowest performance is observed for WB packing. The RP and CF packing being between these two limits. The worst performance of WB packing is attributed to the short contact time between the air and water. On the other side, the comparative performance of RP packing is related to the higher surface area, which maximizes the heat transfer.

Fig 4. (a, b, c, and d) shows the variation of pressure drop and evaporation rate with air and water mass flow rates for the four tested packings. Again, all the curves are drawn for fixed inlet temperatures of the hot water and cold air. 

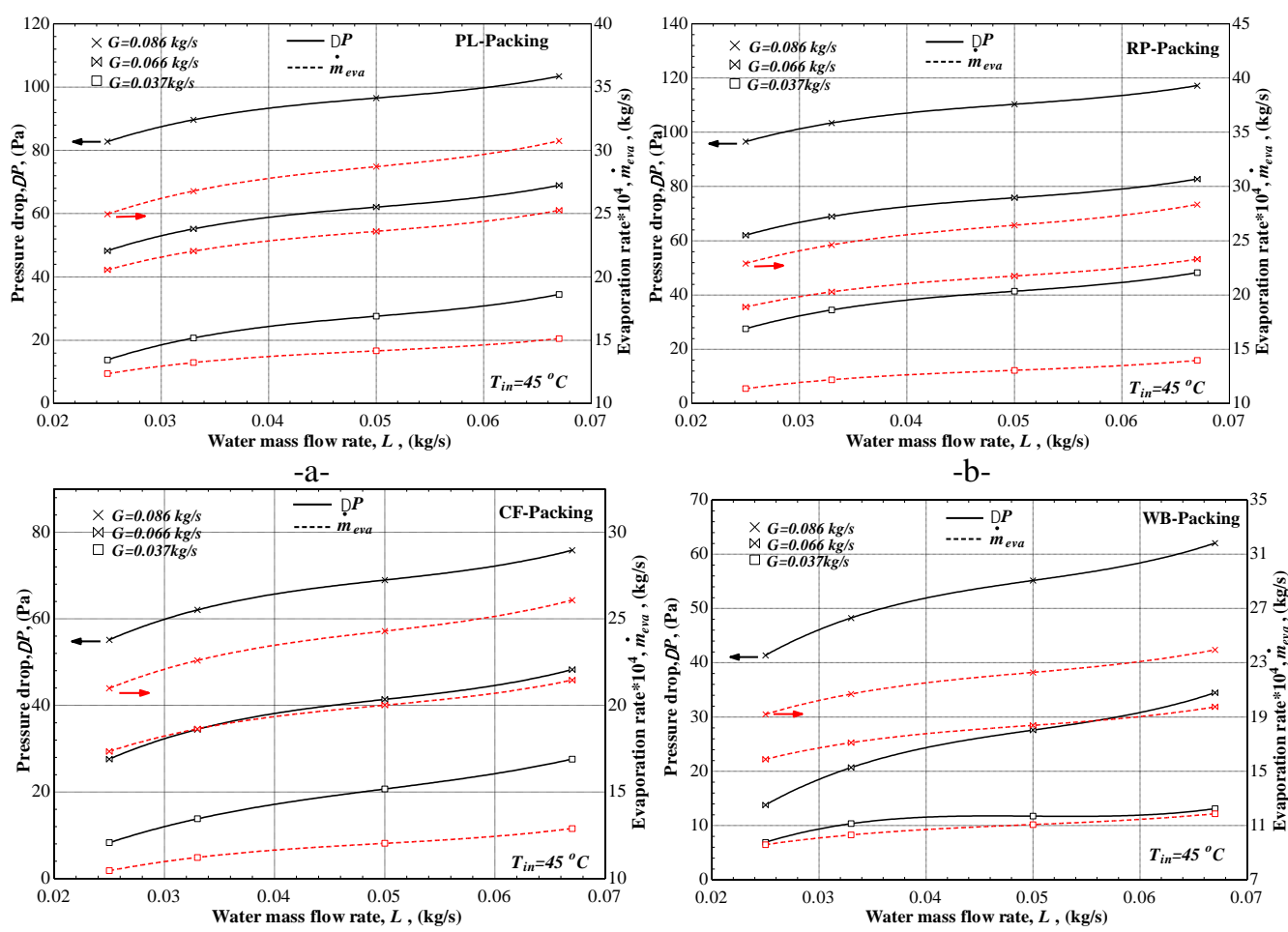

$-\mathrm{c}-$

$-\mathrm{d}-$

Fig. 4. The variation of pressure drop and evaporation rate with air and water mass flow rates (-a-PL, -b-RP, -c-CF, and -d- WB filling).

Increasing air mass flow rate will increase both pressure drop and evaporation rate due to raising the air velocity. Increasing the water flow rate will also increase the pressure drop and evaporation rates, but at lower levels than the effect of air. Rising the hot water flow rate imposes overwork on the tower and it represents an obstruction in the flow of air and so the pressure drop will increase. Generally, the pressure drops, and evaporation rate are in a small range due to the limited capacity of the tower. The figure shows that the RP packing has the largest value of the pressure drop, followed by PL packing, then CF packing, and WB has the lowest recorded pressure drop. Unfortunately, the low-pressure drop for the WB packing is accompanied by the worst thermal performance. The low-pressure drop is mainly due to uniform air distribution across the tower.

Fig 5. shows the effect of hot water temperature on the tower performance in terms of NTU and efficiency for the four tested packing s. The curves are drawn for the best situation of maximum tested air flow rate and minimum hot water flow rate. As the temperature of hot water increases from $45^{\circ} \mathrm{C}$ to $49^{\circ} \mathrm{C}$, both NTU and tower efficiency will decrease due to the increase in heat load applied to the tower. However, the WB packing shows a less decreasing percentage of NTU comparing to the other types of packing. 


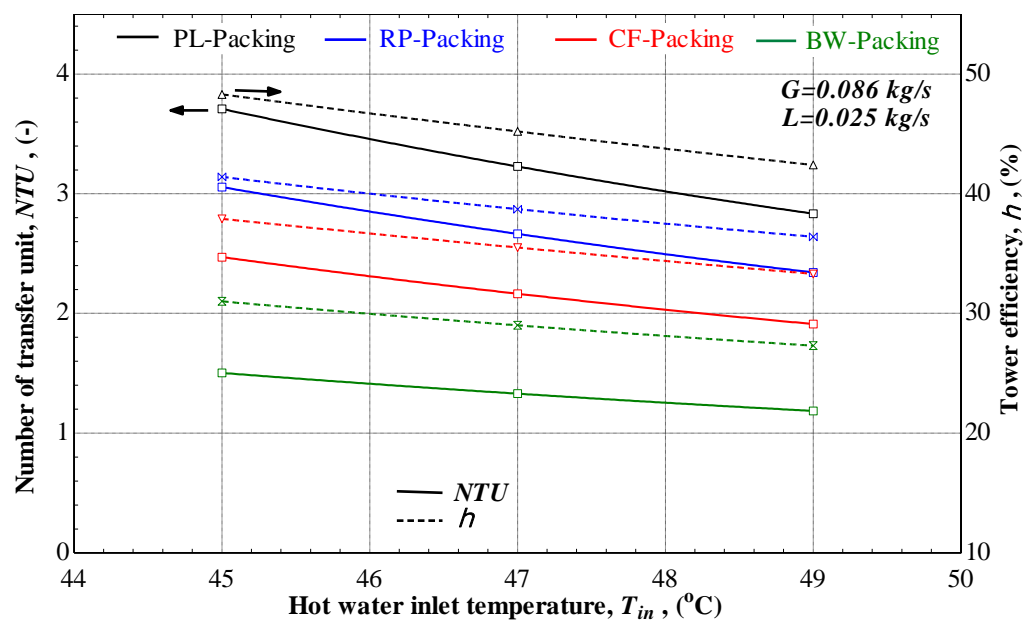

Fig. 5. The variation of NTU and tower efficiency with hot water temperature.

Fig 6. reveals the effect of hot water temperature on the pressure drop and evaporation rate for the four tested packing s. For the three tested hot water temperatures, the pressure drop is constant which is mainly due to the low-temperature range that causes no noticeable change in this parameter. As hot water rises, then the evaporation rate will increase for all the tested packing $\mathrm{s}$ due to the decrease in the latent heat of evaporation. The higher temperature is supposed to cause higher heat transfer since it is the driving force for this phenomenon. Since the air flow rate and its conditions are fixed, then this situation will not be attained.

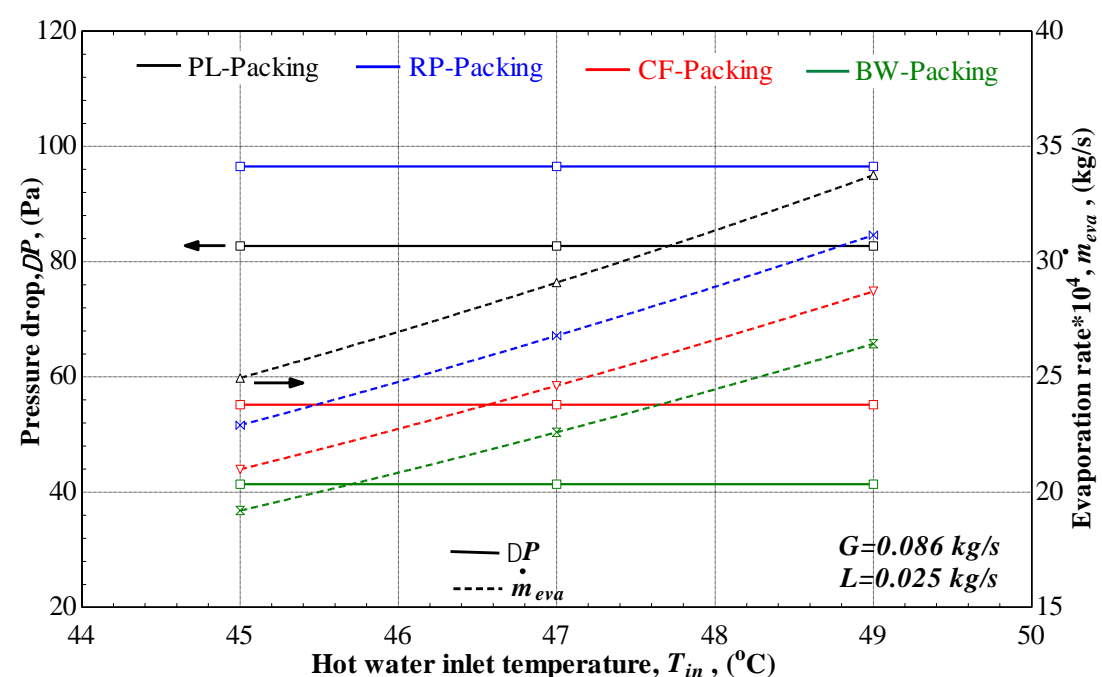

Fig. 6. The variation of pressure drops and evaporation rate with hot water temperature. 


\section{Conclusions}

The present work introduces an experimental study for the performance of wet counter flow cooling using four types of packing $\mathrm{PL}, \mathrm{RP}, \mathrm{CF}$, and WB. The following conclusions are revealed:

1. Increasing air mass flow rate causes better thermal performance of the tower but it also increases the pressure drop. Excessive rate of hot water flow rate caused the performance to degrade and so does its temperature.

2. The PL packing is still the most effective in terms of NTU and efficiency among the tested packings. The comparative packing is RP, then the CF packing comes next. The WB packing was the least performing of the packings. The thermal performance of the suggested packing belongs to its evaporative rate ability.

3. Higher pressure drop is recognized for the RP packing and the WB shows the lowest value of pressure drop.

\section{Acknowledgments}

The authors would like to express their gratitude to Basra Engineering Technical College, Basra, Iraq for their support to do this work.

\section{References}

[1] American Society of Heating, Refrigerating, and Air-Conditioning Engineers. ASHRAE Handbook Heating, Ventilating, and Air-Conditioning- Systems and Equipment. USA.2012.

[2] Merkel F. Verdunstungskuhlung. erste Ausgabe. Berlin: VDI-Verl, 1925.

[3] Baker DR, Shryock HA. A comprehensive approach to the analysis of cooling tower performance. ASME J of heat transfer. 1960; 83(3): 339-349.

[4] Jaber H and Webb RL. Design of cooling towers by the effectiveness-NTU method. J. Heat Transfer. 1989; 111(4): 837-843.

[5] Elsarrag E. "Experimental study and predictions of an induced draft ceramic tile packing cooling tower. Energy Convers. and Manag. 2006; 47: 2034-2043.

[6] Gharagheizi F, Hayati R, Fatemi S. Experimental study on the performance of mechanical cooling tower with two types of film packing. Energy Convers. and Manag. 2007; 48: 277-280.

[7] Mahmoud AF, Ahmed HH, Mahmoud RA. Experimental and theoretical study of cooling tower performance using different types of packing. J. of Eng. and Devel. 2009; 12(4): 21-43.

[8] Lemouari M, Boumaza M, Kaabi A. Experimental analysis of heat and mass transfer phenomena in a direct contact evaporative cooling tower. Energy Convers. and Manag. 2009; 50: 1610-1617.

[9] Abbas MN. Study the performance of different packing in open cooling towervs. J. of Eng. and Devel.2012; 16(2):193-210.

[10] Kariem NO. Effect of changing packing shapes on the evaporation rates using different combination arrangements of dry-wet cooling towers. Al-Qadisiyah J. for Eng. Sci. 2013; 6(2): 232-246.

[11] Ghazani MA, Hosseini AH, Emami MD. A comprehensive analysis of a laboratory scale counter flow wet cooling tower using the first and the second laws of thermodynamics. Appl. Therm. Eng. 2017; $125: 1389-1401$.

[12] Chen LS, Fei BH, Ma XX, Lu JP, and Fang CH. Investigation of bamboo grid packing properties 
used in cooling tower. Forests. 2018; 9 (762):1-9.

[13] Kong QJ, Liu DY, Wang P, Xie DQ, Wu Q, Zhao XY. Experimental study on the heat and mass transfer characteristics of a counter-flow wet cooling tower with foam ceramic packing. Thermophysics and Aeromechanics. 2019; 26 (2): 267-279. 